\title{
Removal of 27 micropollutants by selected wetland macrophytes in hydroponic conditions
}

\author{
Hana Brunhoferova *, Silvia Venditti, Markus Schlienz, Joachim Hansen \\ Department of Engineering, University of Luxembourg, Campus Kirchberg, 6, rue Coudenhove-Kalergi, L-1359, Luxembourg
}

\section{A R T I C L E I N F O}

Handling Editor: Chang-Ping Yu

\section{Keywords:}

Micropollutant removal

Emergent macrophytes

Hydroponic conditions

\begin{abstract}
A B S T R A C T
In this work, the primary focus is given on a mixture of 27 micropollutants (pharmaceuticals, pesticides, herbicides, fungicides and others) and its removal from aqueous solution by phytoremediation. Phytoremediation belongs to technologies, which are contributing on removal of micropollutants from wastewater in constructed wetlands. Constructed wetlands can be used as an additional step for elimination of micropollutants from municipal medium-sized wastewater treatment plants. To our knowledge, such a broad variety of micropollutants was never targeted for removal by phytoremediation before. In this work, we carry out experiments with 3 emergent macrophytes: Phragmites australis, Iris pseudacorus and Lythrum salicaria in hydroponic conditions. The selected plants are exposed to mixture of micropollutants in concentrations $1-14 \mathrm{mg} / \mathrm{l}$ for a time period of 30 days. The highest affinity for phytoremediation is detected at groups of fluorosurfactants (removal rate up to $30 \%$ ), beta-blockers (removal rate up to 50\%) and antibiotics (removal rate up to 90\%). The leading capability for micropollutant uptake is detected at Lythrum salicaria, where 25 out of 27 compounds are removed with more than $20 \%$ efficiency. The results demonstrate well usefulness of this technology e.g. in an additional treatment step, because the mentioned groups of micropollutants are removed with comparable or even higher effectivity, than it is in case of conventional wastewater treatment plants.
\end{abstract}

\section{Introduction}

The use of pharmaceuticals, herbicides, pesticides and other compounds has been increasing in the past decades due to industrialization, agriculture, increased life expectations, etc. This trend creates many technological challenges, as these compounds, so-called micropollutants (MPs) or emerging contaminants, are poorly removed by conventional wastewater treatment plants (WWTPs) and thus may enter the aquatic environment (Carvalho et al., 2012; Grassi et al., 2012; Luo et al., 2014; Ternes et al., 2002; Verlicchi and Zambello, 2014) in relevant concentrations. The presence of MPs in water bodies creates also environmental challenge, as it may lead to negative effects, including spread of antibiotic resistance, short-term and long-term toxicity (Fent et al., 2006; Pruden et al., 2006) and thus also possible impacts on human health (Huerta-Fontela et al., 2011). Nowadays no legal limits regarding MPs in WWTPs effluents have been defined. However, the European Commission has been especially receptive to the topic of MPs contamination and released an updated Watch list (Vella, 2018) with 15 emerging contaminants, including macrolides and hormones. As this list obliges EU member states to monitor emerging contaminants, more European countries started to anticipate future decisions with national and local requirements. As example, the Swiss government identified 100 out of the 700 WWTPs that will be supported with an additional treatment step in order to achieve an average of $80 \%$ removal for selected MPs (Eggen et al., 2014). The upgrade of existing WWTPs with an additional step is considered necessary, so that the presence of MPs in aquatic environment is avoided.

Generally common advanced technologies, such as activated carbon adsorption, advanced oxidation processes and membrane separation are extensively investigated (Y. Li et al., 2014). Unfortunately, these processes have cost-prohibitive background. Constructed wetlands (CWs) are a promising technology especially for treatment of effluent of small and medium-sized WWTPs (Ali and Gupta, 2007; E. Lee et al., 2013; Lizama A. et al., 2011), which is the case for example of the Greater Region (Luxembourg, Wallonia, Rhineland- Palatinate, Saarland, Lorraine). Due to their low cost availability, easy set up and good performance (Janzen et al., 2009; E. Lee et al., 2013; Verlicchi and Zambello, 2014), CWs have been recently exploited in the Interreg Greater Region

\footnotetext{
* Corresponding author.

E-mail address: hana.brunhoferova@uni.lu (H. Brunhoferova).
} 
project 'EmiSûre' (N 013-2-03-049) (Brunhoferova et al, 2019a, 2019b; Knerr et al., 2018) with a planted vertical sub-surface flow configuration. The project led to satisfying results in terms of global removals, however, individual contribution of removal technologies (i.e. sorption, biodegradation, phytoremediation) in CWs was not addressed. Therefore, a methodology has been set up to better quantify the contribution of each elimination mechanism minimizing the cross effect of the other. Particularly, current research intends to determine the mechanism for removal of MPs by specific type of plants, so-called phytoremediation.

Phytoremediation is a clean-up technology, where plants are able to remove pollutants from the environment (Bingöl et al., 2017; McCutcheon et al., 2002; W. Zhang et al., 2019). It is composed from several processes, such as rhizofiltration, phytovolatilization or phytodegradation (Jeevanantham et al., 2019; J. H. Lee, 2013). We suppose that abundant mechanisms in this case could be phytodegradation, as it is most suited for organic chemicals with $\log K_{\mathrm{OW}}=0.5-3.0$ (Schnoor et al., 1995) or phytovolatilization, which suits for low-molecular-weight compounds (Carvalho et al., 2014).

27 compounds are selected based on different criteria: those known to be highly excreted (in the case of pharmaceuticals) or with potential eco-toxicity (i.e. cytostatics), but also those to be under observation in line with the European Commission strategy and KomS guidelines (KomS - Kompetenzzentrum Spurenstoffe, n.d.). To the best of our knowledge, removal of such a wide spectrum of MPs from liquid solution by specific plants has never been targeted before. Three types of emergent macrophytes, Phragmites australis (common reed), Iris pseudacorus (yellow flag) and Lythrum salicaria (purple loosestrife) are investigated. Phragmites australis belongs to the most used plants in CWs thanks to its extensive root and rhizome system (Brix, 2003), and together with Iris pseudacorus and Lythrum salicaria it was used in the EmiSûre project at vertical sub-surface flow configuration of CWs. In case of Phragmites and Iris the advantage of combining long with short roots is considered beneficial as it is expected to increase the uptake of MPs in CWs configuration. Lythrum is known for its ability to build a subterranean system of roots (Stevens et al., 2002) with extensive colonization of arbuscular mycorrhizal fungi (AMF) (Stevens and Peterson, 1996). Symbiotic relationship between plants and AMF increases the ability of the plant to uptake nutrients and pollutants from different media (Calheiros et al., 2019; Dolinar and Gaberščik, 2010; Joner and Leyval, 2009; Stevens and Peterson, 2007). To establish the potential for MPs to be up taken by selected wetland plants, experiments in so-called hydroponic conditions (dos Santos et al., 2013) are carried out.

Hydroponics as technology for plant growth is recently gaining increasing attention, as soil has been identified as a limiting factor for the plant growth (Mamta D. Sardare, 2013; Schnitzler, 2013). It is used in many different areas, such as vertical farming, farms for cultivation of clean, healthy and fresh vegetables, but also in urban environment for reduction of water needs, environmental cultivation and others (Schnitzler, 2013). Usage of Phragmites australis in hydroponics is possible e.g. for gravel beds and treatment of wastewater, which have been already successfully demonstrated (Gagnon et al., 2010) or for removal of personal care products in hydroponics (Ramprasad and Philip, 2018). The knowledge gained about usage of Iris in hydroponics can be in future utilized in removal of e.g. pesticides (Q. Wang et al., 2013). One of the goals of this work is to establish optimal conditions for hydroponics, as this technology has potential in many different areas. The plants are exposed to different conditions not just to optimize the uptake of MPs by the plants, but also the growing conditions themselves.

This work is a part of a PhD research, aiming to quantify mechanisms/technologies in CWs as additional step in terms of MPs' removal from municipal wastewater. It is evident, that the plants themselves do not have such a vigorous capacity regarding elimination of MPs, especially in case of 27 compounds, as CW as a whole unit (Carvalho, 2021; Francini et al., 2018). Therefore, concentrations in ranges of $\mathrm{mg} / \mathrm{l}$ are selected (Kadlec and Wallace, 2009; Lv et al., 2016; Macci et al., 2015), to ensure that the removal by the plants could be measured, as the main aim of the $\mathrm{PhD}$ research is to quantify the removal mechanisms with respect to the selected media's ability, not directly to its application to the real conditions.

The research presented in this publication aims: 1 . to evaluate the potential of the selected macrophytes to remove studied MPs, 2. to assess the differences of adapted and fresh plants on the removal of MPs, 3. to appraise the role of phytoremediation in the removal mechanisms/ technologies of CWs.

\section{Methodology}

\subsection{Components and chemical compounds}

One-liter jars with lid and chemicals needed for preparation of nutrient solution (so-called Hoagland solution (Smart and Barko, 1985)) are purchased at Carl Roth GmbH \& Co. Kg. Three wetland plant species, Phragmites australis, Iris pseudacorus and Lythrum salicaria are from renatur GmbH. A special LED lamp, providing artificial sunlight with 10 light intensities is provided by Lovebay International Limited. Portable meters for analyses of conductivity, oxidation-reduction potential, etc. are purchased at Xylem Analytics Germany Sales GmbH \& Co. KG. For the measurement of the nutrients amount (nitrogen, phosphorus), the Hach Lange test cuvette box is used. 27 MPs compounds (Table 1) are all provided by Techlab, France (purity $>99.99 \%$ ). Compounds for the preparation of the nutrient solution are purchased at Carl Roth, Germany.

\subsection{Plants used for the experiment}

The plants are chosen based on their usage in CWs, which are installed as a polishing step of effluents from 2 WWTPs in Luxembourg (WWTPs Reisdorf and Echternach (Brunhoferova et al., 2019a), 4000 PE and 36000 PE respectively). In the first part, some of the controls are used like 'fresh', meaning that they did not get in contact with any wastewater effluent before and they are received directly from the producer (Phragmites, Iris, Lythrum fresh, controls A, B, C). Other reference plants, Phragmites and Iris, are from Reisdorf WWTPs, where they were exposed to wastewater effluent for 16 months (labeled as Phragmites, Iris adapted, controls D and E). These plants are chosen to evaluate the impact of long-term plant exposition to nutrients and MPs from wastewater effluent. The controls used in the experiment are stated in Table 2.

\subsection{Conditioning phase}

Prior the experiment, a conditioning phase has been considered necessary. For this phase, the soil is removed from the plants to avoid the soaking up of the MPs on the soil and the roots are immersed for $1 \mathrm{~min}$ to MICROPUR MC 1T medium (Carvalho et al., 2012) to inhibit the microbial activity and therefore to exclude the biodegradation and sorption of studied MPs. The antimicrobial medium is removed by rinsing of the roots for $30 \mathrm{~s}$ with Milli-Q water. Hoagland solution is prepared, to ensure a proper nutrition environment for the plant growth in hydroponic conditions. As this solution is designed for plants growing from sediment, where nitrogen and phosphorus source is provided from the substrate, the adaption is needed by adding source of these two missed elements. In the first part of the phytoremediation experiment, $\mathrm{NaNO}_{3}$ and $\mathrm{KH}_{2} \mathrm{PO}_{4}$ are used as a source of nitrogen and phosphorus.

\subsection{Phytoremediation experiment}

After conditioning for one week, the plants are removed from the solution and dead biomass is eliminated. Plants are weighted 4 times: 1) before conditioning phase, 2) after conditioning phase, 3) before removal of dead biomass and 4) after removal of dead biomass. Next, fresh Hoagland solution is prepared and stock solutions of 27 MPs in 
Table 1

Selected micropollutants.

\begin{tabular}{|c|c|c|c|c|}
\hline Group & Substance & CAS number & Therapeutic Group & $\log \mathrm{K}_{\mathrm{ow}}$ \\
\hline \multirow[t]{14}{*}{ Pharmaceuticals } & Atenolol & $29122-68-7$ & Beta Blocker & 0.16 \\
\hline & Bezafibrate & $41859-67-0$ & Lipid regulator & 4.25 \\
\hline & Carbamazepine & $298-46-4$ & Psychiatric drug & 2.45 \\
\hline & Clarythromycin & 81103-11-9 & Antibiotic & 3.16 \\
\hline & Ciprofloxacin & 85721-33-1 & Antibiotic & 0.28 \\
\hline & Cyclophosphamide & $50-18-0$ & Cytostatic & 0.63 \\
\hline & Diclofenac & $15307-86-5$ & Analgesic/anti-inflammatories & 4.51 \\
\hline & Erythromycin & $114-07-8$ & Antibiotic & 8.9 \\
\hline & Ketoprofen & $22071-15-4$ & Analgesic/anti-inflammatories & 3.12 \\
\hline & Lidocaine & $137-58-6$ & Anesthetic & 2.26 \\
\hline & Metoprolol & 51384-51-1 & Beta Blocker & 1.88 \\
\hline & Propranolol & $525-66-6$ & Beta Blocker & 3.48 \\
\hline & $\mathrm{N}$-acetyl sulfamethoxazole & $21312-10-7$ & Metabolite of Sulfamethoxazole & 0.86 \\
\hline & Sulfamethoxazole & $723-46-6$ & Antibiotic & 0.89 \\
\hline Corrosion inhibitor & Benzotriazole & $95-14-7$ & Corrosion inhibitor/Antiviral & 1.44 \\
\hline \multirow[t]{10}{*}{ Pesticides/Herbicides etc. } & Carbendazim & $10605-21-7$ & Fungicide & 1.52 \\
\hline & Deet & $134-62-3$ & Insect repellents & 2.02 \\
\hline & Diuron & $330-54-1$ & Herbicide & 2.68 \\
\hline & Isoproturon & $34123-59-6$ & Herbicide & 2.87 \\
\hline & Terbutryn & $886-50-0$ & Herbicide & 3.74 \\
\hline & Mecoprop & 7085-19-0 & Herbicide & 3.13 \\
\hline & Tris(2-chloroisopropyl)phosphate & $13674-84-5$ & Flame retardant & 2.59 \\
\hline & Tolyltriazole & 29385-43-1 & Fertilizer & 1.08 \\
\hline & Glyphosate & $1071-83-6$ & Herbicide & -3.4 \\
\hline & AMPA (Aminomethylphosphonic acid) & $1066-51-9$ & Degradation product & -1.63 \\
\hline \multirow[t]{2}{*}{ Fluorosurfactants } & Perfluorooctanesulfonic acid (PFOS) & $1763-23-1$ & Surfactant & 4.49 \\
\hline & Perfluorooctanic acid (PFOA) & $335-67-1$ & Surfactant & 4.81 \\
\hline
\end{tabular}

Table 2

Controls used in the experiment.

\begin{tabular}{clllll}
\hline $\begin{array}{l}\text { Label of a } \\
\text { control }\end{array}$ & $\mathrm{A}$ & $\mathrm{B}$ & $\mathrm{C}$ & $\mathrm{D}$ & $\mathrm{E}$ \\
\hline $\begin{array}{c}\text { Type of a } \\
\text { plant }\end{array}$ & $\begin{array}{l}\text { Phragmites } \\
\text { fresh }\end{array}$ & $\begin{array}{l}\text { Iris } \\
\text { fresh }\end{array}$ & $\begin{array}{l}\text { Lythrum } \\
\text { fresh }\end{array}$ & $\begin{array}{l}\text { Phragmites } \\
\text { adapted }\end{array}$ & $\begin{array}{l}\text { Iris } \\
\text { adapted }\end{array}$ \\
\hline
\end{tabular}

concentrations 1-14 mg/1 (Carvalho et al., 2014; Z. Li et al., 2014; Lv et al., 2016; Q. Wang et al., 2013) in methanol are added (4.25\% solution). The jars are then filled to 11 volume with Milli-Q water, covered with aluminium foil and closed with polystyrene lid, to exclude photodegradation. After 10 days of experiment in presence of MPs some phytomass of the plants turned into necromass (dead phytomass (Meuleman et al., 2002) indicating a loss in physiological activity. This is also confirmed with increasing concentrations of soluble nutrients in the growing solution (Boyd, 1970; Godshalk, 1978; Gosselink and Kirby, 1974).

Therefore, the experiments are repeated under following optimized conditions:

- adaptation of Hoagland solution: use of $\mathrm{KNO}_{3}$ instead of $\mathrm{NaNO}_{3}$, since $\mathrm{Na}$ is toxic to plants in concentrations higher than $50 \mathrm{mg} / \mathrm{l}$ (Hydroponic Nutrient Solutions, n.d.);

- prolonged time of conditioning phase (2 weeks instead of 1 week);

- usage of LED lamp providing artificial sunlight, ensuring optimal growing conditions for plants (Hydroponic: Hydroponics - Optimal Growing Conditions, n.d.);

- usage of aluminium 'roof' instead of polystyrene lid, ensuring oxygen input in the studied environment (Hydroponic: Hydroponics Optimal Growing Conditions, n.d.).

The second phase of the experiment is proceeded as described previously, with mentioned modifications on the methodology. The inorganic salts used for the nutrient solution are stated in Supplementary data, Table 2).

\subsection{Sample analysis}

The duration of the phytoremediation experiment is 30 days, samples of $5 \mathrm{ml}$ volume are taken on days $0,1,2,4,7,14$ and 30 . The sampling strategy is planned with respect to plants state, as explained in section 3.2. In this work only samples from the liquid solution are considered, the plants themselves are not exploited to any additional analysis (i.e. tissues examination). The samples are filtered through $0.45 \mu \mathrm{m}$ syringe (Carl Roth $\mathrm{GmbH}$ ). To monitor the uptake of inorganic salts and MPs by plants, concentration of dissolved oxygen and other parameters, $\mathrm{pH}$, electrical conductivity, oxidation-reduction potential are measured on sampling daily base. Between every measurement, the electrodes are washed carefully with Milli-Q water to avoid any crosscontamination. The concentrations of nitrate, phosphate and COD (Hach Lange test cuvette set) are measured on site of the laboratory on each day of sampling as well. After filtration, the samples are frozen to $-20^{\circ} \mathrm{C}$ and then analyzed externally in Luxembourg Institute of Science and Technology (LIST).

The samples are filtered and diluted with water/methanol 90/10, as pre-conditioning is not needed and then immediately analyzed by Liquid Chromatography (1260 Series, Agilent, Santa Clara USA) coupled to triple-quadrupole Mass Spectrometry (QTRAP 4500, AB Sciex, Framingham USA).

The chromatographic separation is carried out on Zorbax Eclipse Plus C18 column, $150 \times 2.1 \mathrm{~mm}$ ID, $3.5 \mu \mathrm{m}$ particle size (Agilent). The flow rate of the mobile phase is constant at $0.25 \mathrm{~mL} / \mathrm{min}$ and the oven temperature remains at $40{ }^{\circ} \mathrm{C}$. The mobile phases used are based on ultrapure water and LC-MS grade acetonitrile buffered with LC-MS grade formic acid $(0.1 \%$, positive mode) or ammonium acetate $(2.5$ $\mathrm{mM}$, negative mode). Considering the target compounds, the mass spectrometer is operated in positive or negative electrospray ionization, in Multiple Reaction Monitoring (MRM) mode. Two MRM transitions are used for each compound of interest, for quantification and confirmation, respectively (Ayoub et al., 2018). Quantitative results are provided thanks to internal calibrations. Quantification limits are provided in Supporting Documents. 


\section{Results and discussion}

\subsection{General parameters}

In the last days of experiment, a high level of COD has been detected (in orders of $\mathrm{g} / \mathrm{l}$ ). High concentration of COD can probably be related to the presence of methanol as a solvent for MPs in the nutrient solution. Additionally, due to inner metabolic plant processes, young plant leaves may produce much higher methanol emissions, than leaves, which already reached maturity (Nemecek-Marshall et al., 1995). Furthermore, mechanical damage, which could happen during the removal of necromass and during the replacement of plants from soil into aqueous solution and also presence of pathogens (Körner et al., 2009) can lead into dramatic increase of methanol concentration (Dorokhov et al., 2018). Besides the facts mentioned above, the stress, to which plants are exposed and slightly higher temperatures (max. $25{ }^{\circ} \mathrm{C}$ ) could lead to increased concentration of biofilm, which could cause in the end effect also slow lysis of plants (confirmed also by decreasing values of oxidation-reduction potential and dissolved oxygen, see supplementary data), accompanied by release of methanol, which is abundantly present in plant cells.

$\mathrm{pH}$ level for all controls have been stable for the whole period of the experiment $(7.0 \pm 0.2)$. The conductivity level remains steady as well, in range between $1100 \pm 100 \mu \mathrm{S} / \mathrm{cm}$. Concentrations of phosphate in the liquid solution remained in all controls $98.0 \pm 2.2 \mathrm{mg} / \mathrm{l}$. For further information, see supplementary data.

Concentration of nitrate in the liquid solution is visibly decreasing from 7th day of operation (Fig. 1).

Nitrate belongs to the most essential nutrients needed for plant growth and as such it is also easily adsorbed by the plants (Bugbee, 2004).

As mentioned in chapter 2.4, the conditions for hydroponic culture have been optimized. Under these optimized conditions, it is observed that controls A, B and C show growth of healthy phytomass, which confirms the right choice of parameters (Fig. 2).

\subsection{Micropollutants}

Due to the fact, that a broad variety of MPs for phytoremediation by different plant species is studied, the exact determination of the removal mechanisms (e.g. volatilization, accumulation) is not the purpose of this

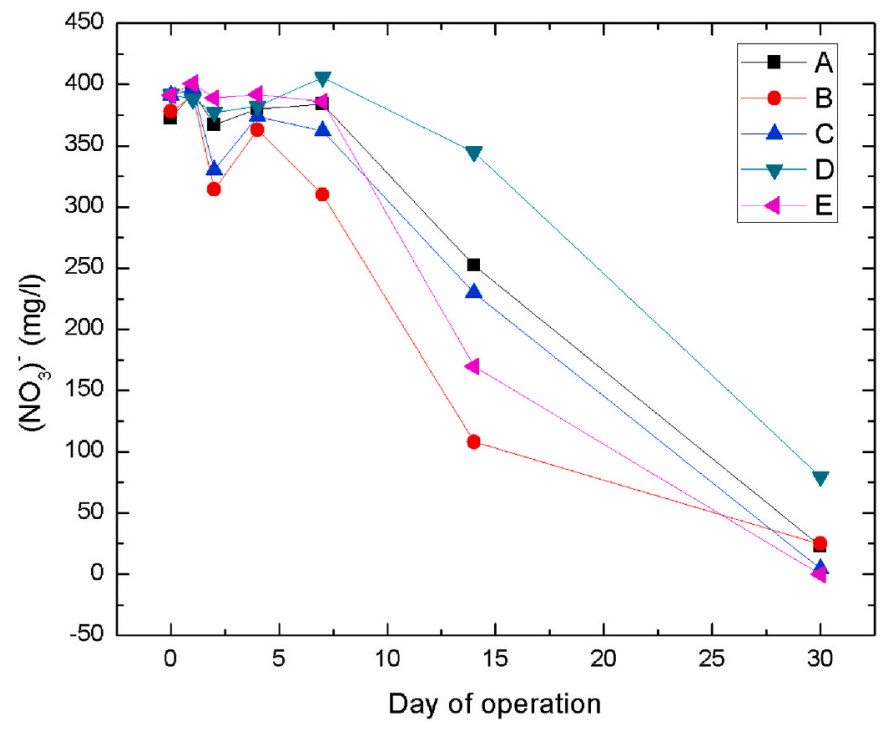

Fig. 1. Decreasing concentration of $\left(\mathrm{NO}_{3}\right)$ - in solutions of all controls $(\mathrm{A}$ Phragmites fresh, B - Iris fresh, C - Lythrum fresh, D - Phragmites adapted, E Iris adapted).

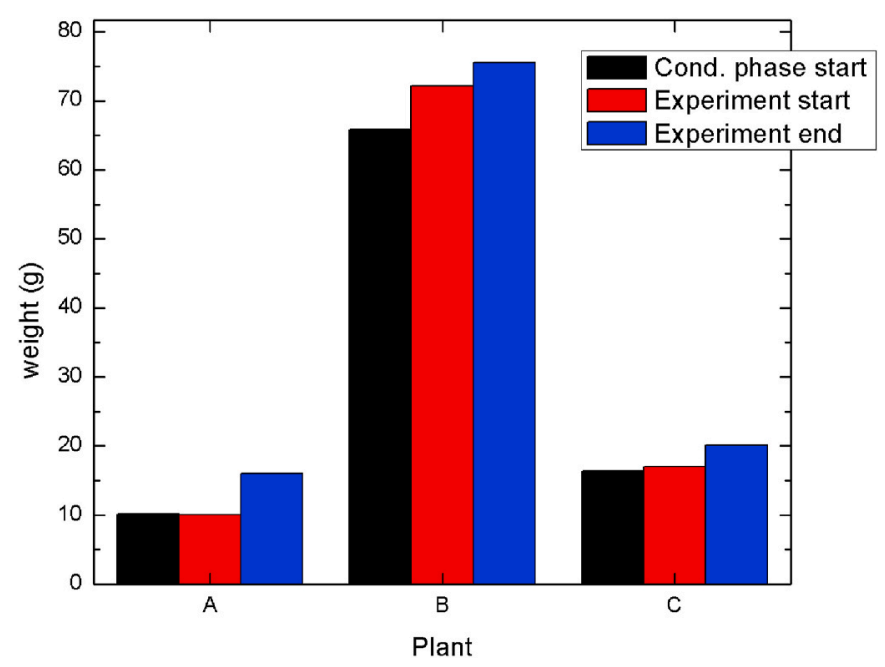

Fig. 2. Growth development of controls A, B and C at the beginning of conditioning phase, at the end of the conditioning phase $=$ at the beginning of the experiment with MPs and at the end of the experiment with MPs.

work. In general, it is known that MPs are accumulated in plants tissues (Migliore et al., 1995), where they can be transported with the translocation stream (e.g. antibiotics (Carvalho et al., 2014), in this case probably ciprofloxacin, clarithromycin, erythromycin), eventually the compounds accumulate also in stems or roots. Low-molecular-weight compounds can be transported through the plant and released from the leaves by phytovolatilization (Carvalho et al., 2014) (in this case possible at e.g. AMPA or benzotriazole). The uptake is dependent on the type of the plants, concentration and character of the MPs. Incorporated to CWs, mentioned removal mechanisms are influenced by the presence of biofilm, animal and microbial communities in the wetland (Carvalho et al., 2012; Harrington and McInnes, 2009; Hijosa-Valsero et al., 2011).

After conditioning phase, at the beginning of the phytoremediation experiment is the uptake of MPs expected to be most rapid, because the plants are already used to hydroponic conditions and they are recovered from the significant change of environment (from soil into liquid solution). This is also confirmed in literature (Lv et al., 2016; Y. Zhang et al., 2017). The phytotoxic effect needs to be considered as well, because some of the MPs, e.g. antibiotics (Carvalho et al., 2014) and herbicides have toxic effect on the plants and this can cause their deteriorative uptake abilities. We suppose, that the longer the plants are exposed to the MPs, the bigger is the phytotoxic effect (accompanied by increasing COD values and decreasing values of oxidation-reduction potential (Yamamoto et al., 2008) and dissolved oxygen (Goto et al., 1996)) and their removal efficiency weakens with time, as shown on case of ciprofloxacin in Fig. 3c). This is a reason why the sampling for MPs content is performed more often at the beginning of the experiment (Lamshoeft et al., 2018; Lv et al., 2016).

Removal rate (r.r.) is calculated from following equation: r.r. (\%) $=$ $\frac{c_{0}-c_{*}}{c_{0}}=100 \%$, where $c_{\mathrm{o}}$ is initial concentration of the MPs and $c$ is the concentration in given day of the experiment. The most surprising fact is, that PFOA and PFOS, which are compounds known to be hardly eliminated from wastewater (Remde and Debus, 1996; S. Zhang and Lerner, 2012) are removed in this experiment with efficiency $15-27 \%$ in case of PFOA (Fig. 3a) and $21-30 \%$ in case of PFOS by both controls of Phragmites. On the other hand, this phenomenon is also shown in literature, where plants exposed to increased concentrations of perfluoroalkyl acids show increased removal of these substances, esp. PFOA (W. Zhang et al., 2019). Iris pseudacorus, shows also remarkable removal efficiency for MPs from group of beta-blockers, especially propranolol (50\%, Fig. 3b), followed by atenolol (35\%) and metoprolol (31\%). Removal efficiencies of beta blockers confirm usefulness of this method as well, because they are comparable or higher, than observed during 

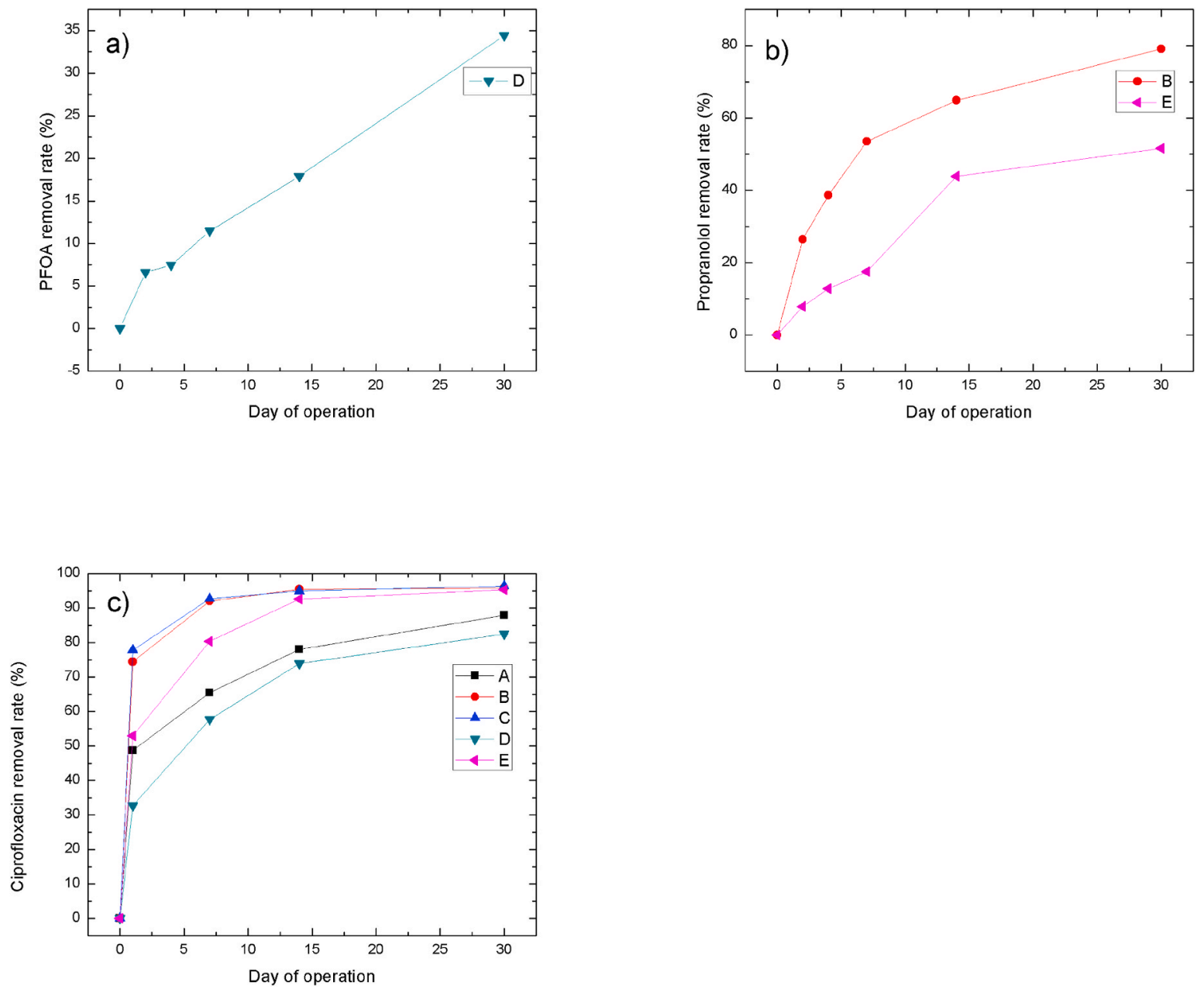

Fig. 3. R. r. of specific MPs: Removal of PFOA by control D (a), removal of propranolol by both types of Iris, B - fresh, E - adapted (b) and removal of ciprofloxacin by all used plants (c).

removal of these compounds in WWTPs e.g. in Canada (Wick et al., 2009). Erythromycin and clarithromycin (macrolide antibiotics), as well as ciprofloxacin (broad fluoroquinolone antibiotic), are removed with high efficiency especially in case of Lythrum and Iris (90\% for ciprofloxacin, $35 \%$ for erythromycin and $32 \%$ for clarithromycin). However, the quantitative determination of macrolides may be affected from experimental uncertainties because possible synthesis intermediates are not measured. Phytoremediation seems to be also relevant especially for ciprofloxacin, which remains in wastewater effluent even after ongoing treatment (Watkinson et al., 2007) and so could be removed by the polishing step applying the plants mentioned in this work. The removal efficiency of all plants is demonstrated in the case of removal of ciprofloxacin (Fig. 3c). Higher passive adsorption of ciprofloxacin by Phragmites australis is observed also by other investigations, when the plant is exposed to higher amounts (mg/l) of this antibiotic (Carvalho et al., 2014; Liu et al., 2013). Compounds, which have lower $\log K_{\text {ow }}$ are more hydrophilic (Cumming and Rü, 2017) (Table 1) and therefore are better soluble in water. These compounds (e.g. atenolol, ciprofloxacin, cyclophosphamide) seem to be better removed by the plants, which is also confirmed in literature (Agostini et al., 2011; Matamoros et al., 2012).

The initial and final concentrations of studied MPs of controls, A - E are stated in Supplementary data. In general, the best removal of MPs is visible in case of the control C - Lythrum fresh, where the highest r. r. of all MPs exceeds 20\%, except of the case of Ketoprofen and AMPA (Fig. 4). However, in case of AMPA the information can be misleading, as AMPA is a degradation product of glyphosate and it has tendency to retransform back to glyphosate (Aparicio et al., 2013; S. Wang et al.,
2016). The ability of Lythrum salicaria to remove pollutants from aqueous solutions has been confirmed in experiments of removal of e.g. heavy metals (Bingöl et al., 2017) and herbicides (Q. Wang et al., 2012).

On the contrary, both cases of Phragmites, fresh (A) and the one adapted to wastewater (D), show the lowest r.r. of all the compounds.

In cases of Phragmites, the average removal ability is higher at the control D, which was used previously for treatment of wastewater effluent in WWTP Reisdorf (esp. in cases of atenolol, clarithromycin and erythromycin, Fig. 5a). Surprisingly, both of these plants show good removal abilities in cases of fluorosurfactants (PFOA 15-27\%, PFOS 21-30\%). In cases of Iris, the r.r. speak in advantage of the control B, the fresh Iris (esp. in cases of beta-blockers, Fig. 5b).

Because Phragmites does not have very dense stems and it has relatively shallow root system (Ge et al., 2017), it grows in so-called reed beds (Kadlec and Wallace, 2009). For our experiments, just single stems with roots are used. That is probably why the removal ability of the control D, Phragmites adapted, is higher, than the ability of the control A, Phragmites fresh, because Phragmites adapted had longer vegetation period, stronger stems and leaves, from the physiological point of view is probably able to uptake bigger amount of MPs. On the other hand, Iris is well known for its strong, bright leaves, growing directly in a fan from the soil (Iris Pseudacorus - UF/IFAS Center for Aquatic and Invasive Plants Archive, n.d.). Both controls, the fresh one and the adapted one, are in a similar physiological status. However, since Iris adapted has been used for treatment of wastewater effluent for 16 months, it is possible that its capabilities to accumulate MPs are not so strong anymore. That might be a reason, why fresh Iris shows better r.r. of 


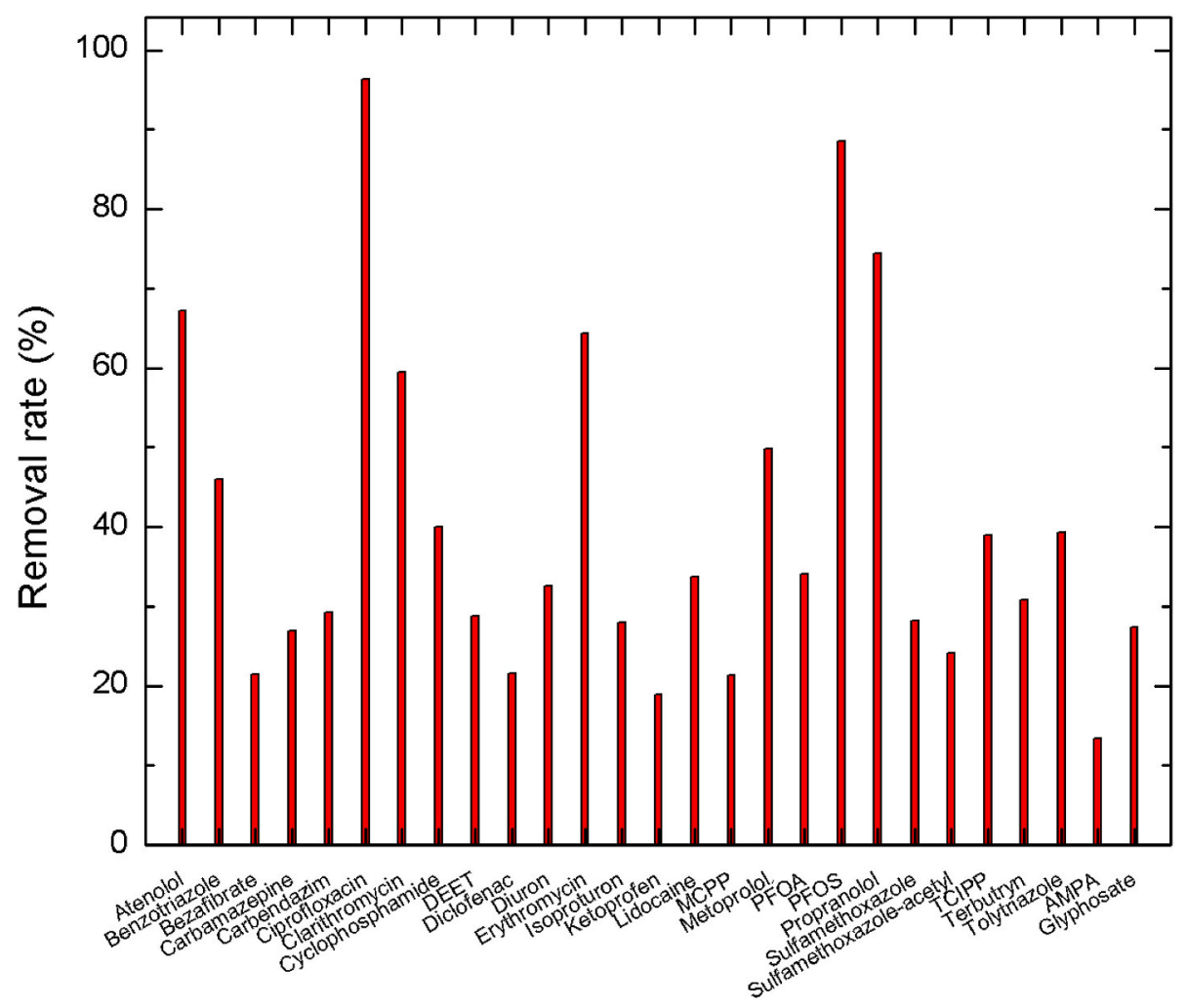

Fig. 4. Removal of 27 compounds by Lythrum salicaria.
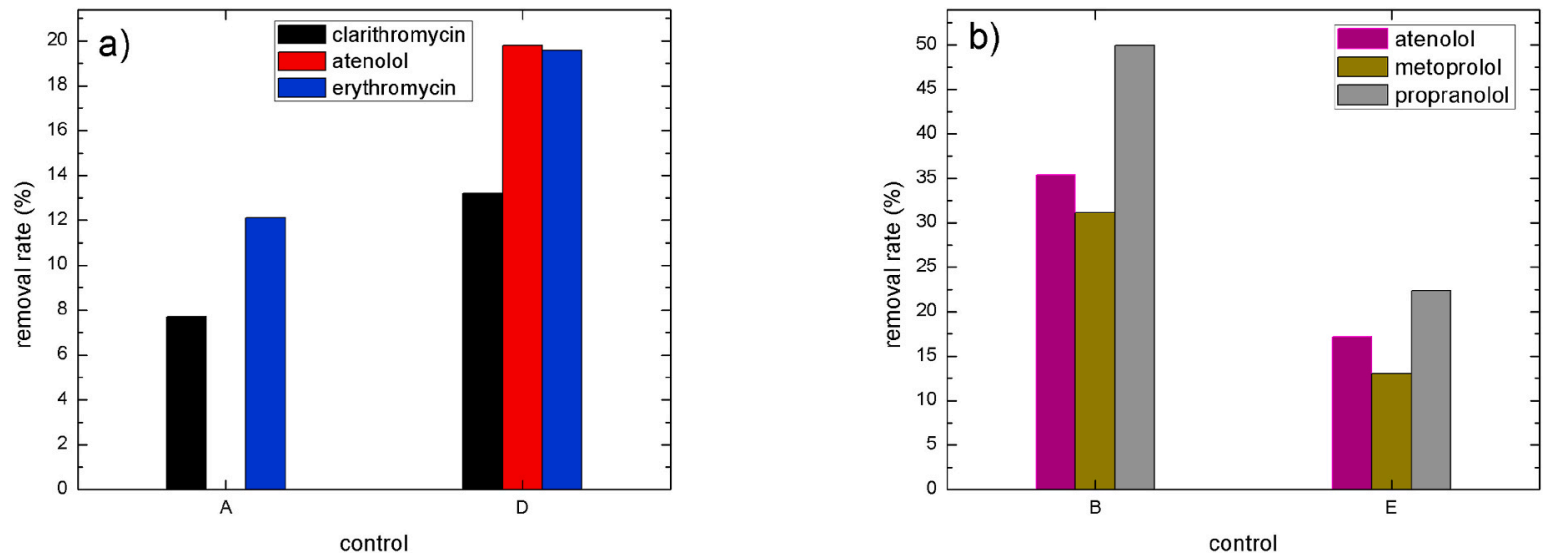

Fig. 5. Comparison of average removal efficiency of controls A vs. D (a) and B vs. E (b).

micropollutants compared to Iris adapted.

\section{Conclusions}

- One of our goals was to establish optimal conditions for the plants in hydroponics, which we determine as: additional support of the plant growth with LED lamp, proper choice of the nutrients, prolonged acclimatization period and ensured oxygen supply. We found out, that stable level of $\mathrm{pH}$ and conductivity are essential for steady conditions of the hydroponic culture as well, which are then preferable for phytoremediation. These findings are helpful for further optimization of hydroponics, which has a broad usage in many domains of the environment.

- Phytoremediation as an independent process seems to be relevant polishing technology for wastewater effluents especially in cases of fluorosurfactants (r.r. up to $30 \%$ ), beta-blockers (r.r. up to $50 \%$ ) and antibiotics (r.r. up to $90 \%$ ).

- In CWs, phytoremediation contributes significantly to overall removal efficiency thanks to the ability of plants to take up specific MPs from wastewater.

- In this experiment, it was found out, that Lythrum salicaria has a potential for further usage in phytoremediation of emergent pollutants from aqueous solutions, because it showed removal efficiency more than $20 \%$ for 25 out of 27 compounds.

- Based on our experience, we recommend to use Phragmites australis for phytoremediation experiments in a more mature state or in higher stem density per $\mathrm{m}^{2}$ (e.g. reed beds), due to its physiological arrangement. On the other hand, we suggest to apply Iris in an early stage of its vegetation state.

These conclusions summarize the main outputs of the work, they 
state clearly the results and give a recommendation for further investigation in phytoremediation processes and optimization of hydroponic conditions.

\section{CRediT author statement}

Joachim Hansen: supervision, funding acquisition, project administration, writing - original draft preparation, writing - reviewing and editing. Markus Schlienz: methodology, conceptualization, writing original draft preparation, resources. Silvia Venditti: supervision, funding acquisition, project administration, writing - original draft preparation, writing - reviewing and editing, formal analysis. Hana Brunhoferova: writing - original draft preparation, writing - reviewing and editing, formal analysis, methodology, conceptualization, investigation, visualization, data curation.

\section{Declaration of competing interest}

The authors declare that they have no known competing financial interests or personal relationships that could have appeared to influence the work reported in this paper.

\section{Acknowledgement}

The presented results are part of Interreg Greater Region, EmiSûre project (N 013-2-03-049). The authors are thankful to the Administration de la Gestion de l'Eau (AGE) allocated at the Ministère de l'Intérieur et de l'Aménagement du Territoire in Luxembourg for supporting and actively contributing to the success of the project. The authors are grateful as well to Luxembourg Institute of Science and Technology for collaboration on the analysis of micropollutants.

\section{Appendix A. Supplementary data}

Supplementary data to this article can be found online at https://doi. org/10.1016/j.chemosphere.2021.130980.

\section{References}

Agostini, E., Talano, M.A., González, P.S., Wevar Oller, A.L., Medina, M.I., 2011. Phytoremediation of phenolic compounds: recent advances and perspectives. In: Handbook of Phytoremediation.

Ali, I., Gupta, V.K., 2007. Advances in water treatment by adsorption technology. Nat. Protoc. 1 (6), 2661-2667. https://doi.org/10.1038/nprot.2006.370.

Aparicio, V.C., De Gerónimo, E., Marino, D., Primost, J., Carriquiriborde, P., Costa, J.L., 2013. Environmental fate of glyphosate and aminomethylphosphonic acid in surface waters and soil of agricultural basins. Chemosphere 93 (9), 1866-1873. https://doi. org/10.1016/j.chemosphere.2013.06.041.

Ayoub, H., Roques-Carmes, T., Potier, O., Koubaissy, B., Pontvianne, S., Lenouvel, A., Guignard, C., Mousset, E., Poirot, H., Toufaily, J., Hamieh, T., 2018. Ironimpregnated zeolite catalyst for efficient removal of micropollutants at very low concentration from Meurthe river. Environ. Sci. Pollut. Control Ser. 25 (35) https:// doi.org/10.1007/s11356-018-1214-0.

Bingöl, N.A., Özmal, F., Akın, B., 2017. Phytoremediation and biosorption potential of Lythrum salicaria L. For nickel removal from aqueous solutions. Pol. J. Environ. Stud. https://doi.org/10.15244/pjoes/70628.

Boyd, C.E., 1970. Losses of mineral nutrients during decomposition of Typha latifolia. Archives of Hyfrobiology 66, 511-517.

Brix, H., 2003. Plants Used in Constructed Wetlands and Their Functions. 1 St. International Seminar on the Use of Aquatic Macrophites for Wastewater Treatment in Constructed Wetlands (December).

Brunhoferova, H., Venditti, S., Hansen, J., 2019a. Impact of Operation Mode for Biochar and Zeolite-Based Planted Vertical Flow Wetlands: How to Enhance the Removal of 27 Micropollutants in Medium-Sized WWTP.

Brunhoferova, H., Venditti, S., Hansen, J., 2019b. ROLE OF TARGETED BIOCHARACTIVATION IN THE REMOVAL OF MACRO- AND MICROPOLLUTANTS FROM SECONDARY EFFLUENT WASTEWATER.

Bugbee, B., 2004. Nutrient management in recirculating hydroponic culture. Acta Hortic. https://doi.org/10.17660/ActaHortic.2004.648.12.

Calheiros, C.S.C., Pereira, S.I.A., Franco, A.R., Castro, P.M.L., 2019. Diverse arbuscular mycorrhizal fungi (AMF) communities colonize plants inhabiting a constructedwetland for wastewater treatment. Water (Switzerland) 11 (8). https:// doi.org/10.3390/w11081535.
Carvalho, P.N., 2021. Constructed wetlands and phytoremediation as a tool for pharmaceutical removal. In: Handbook of Environmental Chemistry, vol. 103. https://doi.org/10.1007/698_2020_624.

Carvalho, P.N., Basto, M.C.P., Almeida, C.M.R., 2012. Potential of Phragmites australis for the removal of veterinary pharmaceuticals from aquatic media. Bioresour. Technol. 116, 497-501. https://doi.org/10.1016/j.biortech.2012.03.066 (July 2010).

Carvalho, P.N., Basto, M.C.P., Almeida, C.M.R., Brix, H., 2014. A review of plant-pharmaceutical interactions: from uptake and effects in crop plants to phytoremediation in constructed wetlands. Environ. Sci. Pollut. Control Ser. 21 (20), 11729-11763. https://doi.org/10.1007/s11356-014-2550-3.

Cumming, H., Rü, C., 2017. Octanol-Water Partition Coefficient Measurement by a Simple 1 H NMR Method. https://doi.org/10.1021/acsomega.7b01102.

Dolinar, N., Gaberščik, A., 2010. Mycorrhizal colonization and growth of Phragmites australis in an intermittent wetland. Aquat. Bot. 93 (2) https://doi.org/10.1016/j. aquabot.2010.03.012.

Dorokhov, Y.L., Sheshukova, E.V., Komarova, T.V., 2018. Methanol in plant life. Front. Plant Sci. 871 (November), 1-6. https://doi.org/10.3389/fpls.2018.01623.

dos Santos, J.D., Lopes da Silva, A.L., da Luz Costa, J., Scheidt, G.N., Novak, A.C., Sydney, E.B., Soccol, C.R., 2013. Development of a vinasse nutritive solution for hydroponics. J. Environ. Manag. https://doi.org/10.1016/j.jenvman.2012.10.045.

Eggen, R.I.L., Hollender, J., Joss, A., Schärer, M., Stamm, C., 2014. Reducing the discharge of micropollutants in the aquatic environment: the benefits of upgrading wastewater treatment plants. Environ. Sci. Technol. 48 (14) https://doi.org/ 10.1021/es500907n.

Fent, K., Weston, A.A., Caminada, D., 2006. Ecotoxicology of human pharmaceuticals. In: Aquatic Toxicology. https://doi.org/10.1016/j.aquatox.2005.09.009.

Francini, A., Mariotti, L., Di Gregorio, S., Sebastiani, L., Andreucci, A., 2018. Removal of micro-pollutants from urban wastewater by constructed wetlands with Phragmites australis and Salix matsudana. Environ. Sci. Pollut. Control Ser. 25 (36) https://doi. org/10.1007/s11356-018-3582-x.

Gagnon, V., Maltais-Landry, G., Puigagut, J., Chazarenc, F., Brisson, J., 2010. Treatment of hydroponics wastewater using constructed wetlands in winter conditions. Water Air Soil Pollut. 212 (1-4), 483-490. https://doi.org/10.1007/s11270-010-0362-8.

Ge, Z., An, R., Fang, S., Lin, P., Li, C., Xue, J., Yu, S., 2017. Phragmites australis + Typha latifolia community enhanced the enrichment of nitrogen and phosphorus in the soil of qin lake wetland. Scientifica. https://doi.org/10.1155/2017/8539093.

W. R. G. Godshalk, G.L., 1978. Decomposition in the literal zone of lakes. In: Freshwater Wetlands: Ecological Processes and Management Potential.

Gosselink, J.G., Kirby, C.J., 1974. Decomposition of salt marsh grass Spartina alterniflora Loisel. Limnol. Oceanogr. 19, 825-832.

Goto, E., Both, A.J., Albright, L.D., Langhans, R.W., Leed, A.R., 1996. Effect of dissolved oxygen concentration on lettuce growth in floating hydroponics. Acta Hortic. 440 https://doi.org/10.17660/ActaHortic.1996.440.36.

Grassi, M., Kaykioglu, G., Belgiorno, V., Lofrano, G., 2012. SpringerBriefs in molecular science - green chemistry for sustainability: ultrasound technology in green chemistry. In: Emerging Compounds Removal from Wastewater. https://doi.org/ 10.1007/978-94-007-2409-9.

Harrington, R., McInnes, R., 2009. Integrated Constructed Wetlands (ICW) for livestock wastewater management. Bioresour. Technol. 100 (22) https://doi.org/10.1016/j. biortech.2009.06.007.

Hijosa-Valsero, M., Sidrach-Cardona, R., Martín-Villacorta, J., Cruz Valsero-Blanco, M., Bayona, J.M., Bécares, E., 2011. Statistical modelling of organic matter and emerging pollutants removal in constructed wetlands. Bioresour. Technol. 102 (8) https://doi.org/10.1016/j.biortech.2011.01.063.

Huerta-Fontela, M., Galceran, M.T., Ventura, F., 2011. Occurrence and removal of pharmaceuticals and hormones through drinking water treatment. Water Research. https://doi.org/10.1016/j.watres.2010.10.036.

Hydroponic, 2021. Hydroponics - Optimal Growing Conditions (n.d.). Retrieved March 8. from. https://www.hydroponic-urban-gardening.com/hydroponics-guide/hydr oponics-optimal-growing-conditions/? $\mathrm{L}=1$.

Hydroponic Nutrient Solutions. (n.d.). Retrieved June 16, 2020, from https://www. smart-fertilizer.com/articles/hydroponic-nutrient-solutions/.

Iris pseudacorus, 2020. UF/IFAS Center for Aquatic and Invasive Plants Archive (n.d.). Retrieved September 24. from. https://plants-archive.ifas.ufl.edu/plant-directory/iri s-pseudacorus/.

Janzen, N., Banzhaf, S., Scheytt, T., Bester, K., 2009. Vertical flow soil filter for the elimination of micro pollutants from storm and waste water. Chemosphere 77 (10), 1358-1365. https://doi.org/10.1016/j.chemosphere.2009.09.024.

Jeevanantham, S., Saravanan, A., Hemavathy, R.V., Kumar, P.S., Yaashikaa, P.R., Yuvaraj, D., 2019. Removal of toxic pollutants from water environment by phytoremediation: a survey on application and future prospects. Environmental Technology and Innovation 13, 264-276. https://doi.org/10.1016/j. eti.2018.12.007.

Joner, E.J., Leyval, C., 2009. Phytoremediation of organic pollutants using mycorrhizal plants: a new aspect of rhizosphere interactions. Sustainable Agriculture. https:// doi.org/10.1007/978-90-481-2666-8_54.

Kadlec, R.H., Wallace, S.D., 2009. Treatment Wetlands, second ed. In: Treatment Wetlands, second ed. https://doi.org/10.1201/9781420012514

Knerr, H., Srednoselec, I., Schmitt, T., Hansen, J., Venditti, S., 2018. Entwicklung von Strategien zur Reduzierung des Mikroschadstoffeintrags in Gewässer im deutschluxemburgischen Grenzgebiet. Wasser, 12.

KomS, 2020. Kompetenzzentrum Spurenstoffe. (n.d.). Retrieved December 14. https://ko ms-bw.de/.

Körner, E., Von Dahl, C.C., Bonaventure, G., Baldwin, I.T., 2009. Pectin methylesterase NaPME1 contributes to the emission of methanol during insect herbivory and to the 
elicitation of defence responses in Nicotiana attenuata. J. Exp. Bot. https://doi.org/ 10.1093/jxb/erp106.

Lamshoeft, M., Gao, Z., Resseler, H., Schriever, C., Sur, R., Sweeney, P., Webb, S., Zillgens, B., Reitz, M.U., 2018. Evaluation of a novel test design to determine uptake of chemicals by plant roots. Sci. Total Environ. 613-614. https://doi.org/10.1016/j. scitotenv.2017.08.314.

Lee, E., Lee, S., Park, J., Kim, Y., Cho, J., 2013. Removal and transformation of pharmaceuticals in wastewater treatment plants and constructed wetlands. Drink. Water Eng. Sci. 6 (2), 89-98. https://doi.org/10.5194/dwes-6-89-2013.

Lee, J.H., 2013. An overview of phytoremediation as a potentially promising technology for environmental pollution control. Biotechnol. Bioproc. Eng. 18 (3), 431-439. https://doi.org/10.1007/s12257-013-0193-8.

Li, Y., Zhu, G., Ng, W.J., Tan, S.K., 2014a. A review on removing pharmaceutical contaminants from wastewater by constructed wetlands: design, performance and mechanism. Sci. Total Environ. 468-469 https://doi.org/10.1016/j. scitotenv.2013.09.018.

Li, Z., Xiao, H., Cheng, S., Zhang, L., Xie, X., Wu, Z., 2014b. A comparison on the phytoremediation ability of triazophos by different macrophytes. J. Environ. Sci. (China). https://doi.org/10.1016/S1001-0742(13)60417-9.

Liu, L., Liu, Y.H., Liu, C.X., Wang, Z., Dong, J., Zhu, G.F., Huang, X., 2013. Potential effect and accumulation of veterinary antibiotics in Phragmites australis under hydroponic conditions. Ecol. Eng. 53, 138-143. https://doi.org/10.1016/j. ecoleng.2012.12.033.

Lizama, A.K., Fletcher, T.D., Sun, G., 2011. Removal processes for arsenic in constructed wetlands. Chemosphere 84 (8), 1032-1043. https://doi.org/10.1016/j. chemosphere.2011.04.022.

Luo, Y., Guo, W., Ngo, H.H., Nghiem, L.D., Hai, F.I., Zhang, J., Liang, S., Wang, X.C., 2014. A review on the occurrence of micropollutants in the aquatic environment and their fate and removal during wastewater treatment. Sci. Total Environ. 473-474, 619-641. https://doi.org/10.1016/j.scitotenv.2013.12.065.

Lv, T., Zhang, Y., Casas, M.E., Carvalho, P.N., Arias, C.A., Bester, K., Brix, H., 2016. Phytoremediation of imazalil and tebuconazole by four emergent wetland plant species in hydroponic medium. Chemosphere 148, 459-466. https://doi.org/ 10.1016/j.chemosphere.2016.01.064.

Macci, C., Peruzzi, E., Doni, S., Iannelli, R., Masciandaro, G., 2015. Ornamental plants for micropollutant removal in wetland systems. Environ. Sci. Pollut. Control Ser. 22 (4) https://doi.org/10.1007/s11356-014-2949-x.

Mamta, D., Sardare, S.V.A., 2013. A review on plant without soil - hydroponics. Int. J. Renew. Energy Technol. 2 (3), 299-304. https://doi.org/10.15623/ ijret.2013.0203013.

Matamoros, V., Nguyen, L.X., Arias, C.A., Salvadó, V., Brix, H., 2012. Evaluation of aquatic plants for removing polar microcontaminants: a microcosm experiment. Chemosphere 88 (10). https://doi.org/10.1016/j.chemosphere.2012.04.004.

McCutcheon, S.C., Susarla, S., Medina, V.F., 2002. Phytoremediation: an ecological solution to organic chemical contamination. Ecol. Eng. 18 (5), 647-658.

Meuleman, A.F.M., Beekman, J.P., Verhoeven, J.T.A., 2002. Nutrient retention and nutrient-use efficiency in Phragmites australis stands after wasterwater application. In: Society of Wetland Scientists, pp. 712-721. https://doi.org/10.1672/0277-5212 (2002)022[0712:NRANUE]2.0.CO;2.

Migliore, L., Brambilla, G., Cozzolino, S., Gaudio, L., 1995. Effect on plants of sulphadimethoxine used in intensive farming (Panicum miliaceum, Pisum sativum and Zea mays). Agric. Ecosyst. Environ. 52 (2-3) https://doi.org/10.1016/01678809(94)00549-T.

Nemecek-Marshall, M., MacDonald, R.C., Franzen, J.J., Wojciechowsk, C.L., Fall, R., 1995. Methanol emission from leaves. Enzymatic detection of gas-phase methanol and relation of methanol fluxes to stomatal conductance and leaf development. Plant Physiol. https://doi.org/10.1104/pp.108.4.1359.

Pruden, A., Pei, R., Storteboom, H., Carlson, K.H., 2006. Antibiotic resistance genes as emerging contaminants: studies in northern Colorado. Environmental Science and Technology. https://doi.org/10.1021/es0604131.
Ramprasad, C., Philip, L., 2018. Contributions of various processes to the removal of surfactants and personal care products in constructed wetland. Chem. Eng. J. 334 https://doi.org/10.1016/j.cej.2017.09.106.

Remde, A., Debus, R., 1996. Biodegradability of fluorinated surfactants under aerobic and anaerobic conditions. Chemosphere. https://doi.org/10.1016/0045-6535(96) 00066-5.

Schnitzler, W.H., 2013. Urban hydroponics for green and clean cities and for food security. Acta Hortic. 1004 (September 2012), 13-26. https://doi.org/10.17660/ ActaHortic.2013.1004.1.

Schnoor, J.L., Licht, L.A., McCUTCHEON, S.C., Wolfe, N.L., Carreira, L.H., 1995. Phytoremediation of organic and nutrient contaminants. Environ. Sci. Technol. 29 (7), 318-323. https://doi.org/10.1021/es00007a002.

Stevens, K.J., Peterson, R.L., 2007. Relationships among three pathways for resource acquisition and their contribution to plant performance in the emergent aquatic plant Lythrum salicaria (L.). Plant Biol. 9 (6) https://doi.org/10.1055/s-2007965079.

Stevens, Kevin J., Peterson, R.L., 1996. The effect of a water gradient on the vesiculararbuscular mycorrhizal status of Lythrum salicaria L. (purple loosestrife). Mycorrhiza 6 (2). https://doi.org/10.1007/s005720050113.

Stevens, Kevin J., Peterson, R.L., Reader, R.J., 2002. The aerenchymatous phellem of Lythrum salicaria (L.): a pathway for gas transport and its role in flood tolerance. Ann. Bot. 89 (5) https://doi.org/10.1093/aob/mcf088.

Ternes, T.A., Meisenheimer, M., McDowell, D., Sacher, F., Brauch, H.J., Haist-Gulde, B., Preuss, G., Wilme, U., Zulei-Seibert, N., 2002. Removal of pharmaceuticals during drinking water treatment. Environ. Sci. Technol. 36 (17), 3855-3863. https://doi. org/10.1021/es015757k.

Vella, K., 2018. COMMISSION IMPLEMENTING DECISION (EU) 2018/840 of 5 june 2018. In: Off. J. Eur. Union, vol. 141 (Issue June)).

Verlicchi, P., Zambello, E., 2014. How efficient are constructed wetlands in removing pharmaceuticals from untreated and treated urban wastewaters? A review. Sci. Total Environ. 470-471, 1281-1306. https://doi.org/10.1016/j.scitotenv.2013.10.085.

Wang, Q., Yang, J., Li, C., Xiao, B., Que, X., 2013. Influence of initial pesticide concentrations in water on chlorpyrifos toxicity and removal by Iris pseudacorus. Water Sci. Technol. https://doi.org/10.2166/wst.2013.071.

Wang, Q., Zhang, W., Li, C., Xiao, B., 2012. Phytoremediation of atrazine by three emergent hydrophytes in a hydroponic system. Water Science and Technology. https://doi.org/10.2166/wst.2012.320.

Wang, S., Seiwert, B., Kästner, M., Miltner, A., Schäffer, A., Reemtsma, T., Yang, Q., Nowak, K.M., 2016. (Bio)degradation of glyphosate in water-sediment microcosms a stable isotope co-labeling approach. Water Res. 99, 91-100. https://doi.org/ 10.1016/j.watres.2016.04.041.

Watkinson, A.J., Murby, E.J., Costanzo, S.D., 2007. Removal of antibiotics in conventional and advanced wastewater treatment: implications for environmental discharge and wastewater recycling. Water Res. 41 (18), 4164-4176. https://doi. org/10.1016/j.watres.2007.04.005.

Wick, A., Fink, G., Joss, A., Siegrist, H., Ternes, T.A., 2009. Fate of Beta Blockers and Psycho-Active Drugs in Conventional Wastewater Treatment. Water Research. https://doi.org/10.1016/j.watres.2008.11.031.

Yamamoto, T., Goto, I., Kawaguchi, O., Minagawa, K., Ariyoshi, E., Matsuda, O., 2008. Phytoremediation of shallow organically enriched marine sediments using benthic microalgae. Mar. Pollut. Bull. 57 (1-5) https://doi.org/10.1016/j. marpolbul.2007.10.006.

Zhang, S., Lerner, D.N., 2012. Review of physical and chemical properties of Perfluorooctanyl Sulphonate (PFOS) with respect to its potential contamination on the environment. Adv. Mater. Res. 518 (523), 2183-2191. https://doi.org/10.4028 /www.scientific.net/AMR.518-523.2183.

Zhang, W., Zhang, D., Zagorevski, D.V., Liang, Y., 2019. Exposure of Juncus effusus to seven perfluoroalkyl acids: uptake, accumulation and phytotoxicity. Chemosphere 233. https://doi.org/10.1016/j.chemosphere.2019.05.258.

Zhang, Y., Lv, T., Carvalho, P.N., Zhang, L., Arias, C.A., Chen, Z., Brix, H., 2017. Ibuprofen and iohexol removal in saturated constructed wetland mesocosms. Ecol. Eng. 98, 394-402. https://doi.org/10.1016/j.ecoleng.2016.05.077. 